Gut, 1970, 11, 27-33

\title{
Absorption and secretion of water and electrolytes by the intact human colon in diffuse untreated proctocolitis ${ }^{1}$
}

\author{
J. HARRIS ${ }^{2}$ AND R. SHIELDS 3
}

From the Department of Surgery, Welsh National School of Medicine, and United Cardiff Hospitals, Cardiff

SUMMARY The net transport and unidirectional fluxes of water, sodium, and potassium were studied in four subjects with diffuse untreated proctocolitis, by perfusing the colon with isotopically-labelled solution instilled through a tube introduced by mouth. The results were compared to those obtained in 13 healthy subjects.

In proctocolitis the colonic absorption of sodium and water was impaired and the secretion of potassium increased. The movement of electrolytes across the colonic mucosa into the lumen was increased and the movement in the opposite direction reduced. The close correlation between water and sodium absorption in healthy subjects was maintained in those with proctocolitis.

These alterations in the colonic handling of water and electrolytes diminish the reserve capacity of the colon and may explain the diarrhoea of proctocolitis.

A prominent feature of proctocolitis is diarrhoea, which, when excessive, may lead to severe losses of water and electrolytes from the body (Coghill, Lubran, McAllen, Edwards, and Richenberg, 1956; Lennard-Jones and Vivian, 1960; Gallagher, Goulston, Wyndham, and Morrow, 1962). However, the cause of the diarrhoea remains obscure.

One explanation may be that the absorption of water and electrolytes by the ulcerated colon is impaired. The only previous direct investigation of absorption and secretion of fluid and electrolytes in proctocolitis was made by Duthie, Watts, de Dombal, and Goligher (1964) who

\footnotetext{
${ }^{1}$ A preliminary communication of this work was read to the British Society of Gastroenterology, November 1967.

'Present address: Department of Surgery, University College Hospital, London.

'Present address: Department of Surgery, University of Liverpool.
}

studied segments of bowel isolated at colectomy. Their technique has, however, two main limitations: only one type of disease can be studiedthat which requires colectomy; and difficulty may be encountered in obtaining control data from healthy subjects.

To study the intact colon of conscious subjects in health or with proctocolitis of varying extent and severity, we have used the technique of colonic perfusion introduced by Levitan, Fordtran, Burrows, and Ingelfinger (1962). The rates at which water and electrolytes are exchanged in both directions across the colonic mucosa (Visscher, Fetcher, Carr, Gregor, Bushey, and Barker, 1944a; Visscher, Varco, Carr, Dean, and Erickson, 1944b) can be measured by incorporating isotopes in the perfused solution (Shields, 1966).

In this paper we report a study of the colonic 
absorption of sodium, potassium, and water in patients with diffuse and untreated proctocolitis. The results are compared with those obtained in healthy subjects.

\section{Methods}

\section{PATIENTS}

We studied four patients, of whom three were male, with proctocolitis involving the entire colon. In three (patients A, B, and D) the disease was severe, and in one (patient $C$ ) moderately severe, according to the classification of Truelove and Witts (1955). The ages of the patients ranged from 27 to 69 years.

At the time of the study none of the patients was depleted of water and electrolytes. The concentrations of sodium in the serum ranged from 133 to 137 m-equiv per litre and of potassium from 3.9 to 4.6 m-equiv per litre. All patients were taking a normal ward diet and were not receiving any specific treatment before or during the study.

\section{HEALTHY SUBJECTS}

Observations were made in 13 healthy male medical students (age range, 19-23 years) who were receiving a diet similar to that of the patients.

Consent was obtained from all subjects according to the principles laid down by the Medical Research Council (1964).
ABSORPTION STUDIES

The details of the method have already been described (Shields, 1966).

Briefly, the subject swallowed a long polyvinyl tube until its tip was seen radiologically to lie in the caecum. A small quantity of sodium diatrizoate (Gastrografin) was injected through the tube to ensure that colonic content did not reflux into the ileum. The colon was then perfused with a solution of sodium chloride $(0.9 \% \mathrm{w} / \mathrm{v})$ at $37^{\circ} \mathrm{C}$ to clear the lumen of faecal debris.

When the rectal effluent was clear, test solution at $37^{\circ} \mathrm{C}$ was instilled through the tube into the caecum by means of a constant infusion pump at a rate of 25 to $30 \mathrm{ml}$ per minute. Usually 4-5 1 of test solution was infused over two to two and a half hours. The perfusate was collected in 10minute aliquots by means of a wide-bore tube inserted through the anus. Rectal effluents were analysed only when steady state conditions were reached, that is, when the composition of the perfusate varied minimally with time (Devroede and Phillips, 1969a). Generally specimens collected during the first hour of perfusion were discarded.

The test solution was modified Tyrode's solution (Code and McIntire, 1956) containing deuterium oxide $(1 \% \mathrm{v} / \mathrm{v})$ and the radioactive isotopes of sodium $\left({ }^{24} \mathrm{Na}, 2 \mu \mathrm{c}\right.$ per litre) and potassium $\left({ }^{42} \mathrm{~K}, 4 \mu \mathrm{c}\right.$ per litre). Polyethylene glycol 4000 (PEG, $1 \mathrm{~g} \mathrm{w} / \mathrm{v})$ was used as a volume indicator.

In the test solution and in the aliquots of rectal

\begin{tabular}{|c|c|c|c|}
\hline \multirow[b]{2}{*}{ Subject } & \multicolumn{3}{|c|}{ Sodium (ll-equiv/min) } \\
\hline & $\mathrm{Net}^{2}$ & Out of Lumen & Into Lumen \\
\hline $\begin{array}{l}\text { Proctocolitis } \\
\text { A }(\mathrm{n}=12)^{1} \\
\text { B }(\mathrm{n}=13) \\
C(\mathrm{n}=9) \\
\mathrm{D}(\mathrm{n}=4)\end{array}$ & $\begin{array}{l}+51 \pm 140 \\
-56 \pm 42 \\
+179 \pm 90 \\
+276 \pm 210\end{array}$ & $\begin{array}{l}514 \pm 108 \\
272 \pm 72 \\
402 \pm 128 \\
564 \pm 64\end{array}$ & $\begin{array}{l}464 \pm 115 \\
328 \pm 88 \\
223 \pm 129 \\
288 \pm 158\end{array}$ \\
\hline Grand mean $\pm S D$ & $+113 \pm 145$ & $438 \pm 130$ & $326 \pm 102$ \\
\hline $\begin{array}{l}\text { Healthy Subjects } \\
1(\mathrm{n}=11) \\
2(\mathrm{n}=5) \\
3(\mathrm{n}=9) \\
4(\mathrm{n}=12) \\
5(\mathrm{n}=7) \\
6(\mathrm{n}=8) \\
7(\mathrm{n}=4) \\
8(\mathrm{n}=8) \\
9(\mathrm{n}=5) \\
10(\mathrm{n}=4) \\
11(\mathrm{n}=3) \\
12(\mathrm{n}=4) \\
13(\mathrm{n}=3)\end{array}$ & $\begin{array}{l}+257 \pm 166 \\
+477 \pm 125 \\
+360 \pm 111 \\
+392 \pm 120 \\
+365 \pm 70 \\
+408 \pm 39 \\
+746 \pm 88 \\
+494 \pm 196 \\
+305 \pm 82 \\
+538 \pm 131 \\
+268 \pm 51 \\
+285 \pm 37 \\
+182 \pm 35\end{array}$ & $\begin{array}{l}615 \pm 153 \\
699 \pm 114 \\
512 \pm 130 \\
615 \pm 170 \\
587 \pm 115 \\
562 \pm 72 \\
791 \pm 96 \\
713 \pm 214 \\
472 \pm 139 \\
697 \pm 245 \\
499 \pm 32 \\
573 \pm 99 \\
415 \pm 51\end{array}$ & $\begin{array}{r}359 \pm 142 \\
221 \pm 133 \\
152 \pm 40 \\
222 \pm 118 \\
222 \pm 65 \\
153 \pm 42 \\
45 \pm 30 \\
219 \pm 161 \\
167 \pm 69 \\
160 \pm 126 \\
231 \pm 35 \\
288 \pm 72 \\
234 \pm 26\end{array}$ \\
\hline Grand mean \pm SD & $+391 \pm 148$ & $596 \pm 108$ & $206 \pm 75$ \\
\hline $\begin{array}{l}\text { Difference between means } \pm S E \\
t\end{array}$ & $\begin{array}{l}+278 \pm 84 \\
3 \cdot 31\end{array}$ & $\begin{array}{l}158 \pm 64 \\
2 \cdot 45\end{array}$ & $\begin{array}{l}120 \pm 46 \\
-2 \cdot 60\end{array}$ \\
\hline $\mathbf{P}$ & $<0.01$ & $<0.05$ & $<0.02$ \\
\hline
\end{tabular}

Table The mean rates $( \pm S D)$ of net transport and of unidirectional flux of sodium, potassium, and water in patients with proctocolitis and in healthy subjects

${ }^{2}$ n represents the number of consecutive 10 -minute collection periods in each subject. 'Plus sign preceding mean rate indicates absorption, minus sign, secretion. 
effluent the separate activities of radioactive sodium and potassium were determined by simultaneous counting in beta and gamma liquid counters (Veall and Vetter, 1958), and the concentrations of deuterium oxide in an infrared spectrometer using a modification (Shields, Mulholland, and Elmslie, 1966) of the method of Berglund-Larsson (1956). The concentration of PEG was estimated by the method of Hydén (1955).

\section{CALCULATIONS}

Sodium, potassium, and water are simultaneously exchanged in both directions across the colonic mucosa. For each substance the difference between the rates of unidirectional movement is referred to as its 'net' transport. The term 'absorption' is restricted to net transport where more of the substance leaves the intestinal lumen and enters the body than moves in the opposite direction; by convention, the rate of absorption is preceded by a plus sign. When more of the substance enters the intestinal lumen than leaves during a period of time, the net transport is referred to as 'secretion', whose rate is preceded by a minus sign. Terminology is discussed in greater detail elsewhere (Shields, 1964).

In each patient, the rates of net transport and of the unidirectional fluxes of water and electrolytes for each 10-minute collection period were calculated on a digital computer using previously described formulas (Shields, 1966). Subsequently the data were analysed in two ways. First in each subject the rates of transport for consecutive collection periods were pooled so that the mean rates for each subject were obtained. The grand means of the rates for the control group and for the patients with proctocolitis were then calculated and compared, using Student's $t$ test (Table). Second, the mean rates for each collection period were calculated so that any systematic change in absorption during the course of the perfusion could be appreciated; the differences between the patients and the healthy subjects were again defined, using the $t$ test (Figs. 1 and 2).

We have previously shown that PEG 4000 is a valid volume indicator in the healthy and diseased human colon (Shields, Harris, and Davies, 1968).

\section{Results}

\section{RATES OF TRANSPORT ACROSS THE COLONIC MUCOSA \\ Net transport}

During perfusion with test solution the healthy colon absorbed sodium and water at mean rates of 0.39 m-equiv and $1.9 \mathrm{ml}$ per minute (Table). In all subjects but one, potassium was secreted into the colonic lumen, the mean rate of secretion being 0.003 m-equiv per minute.

In four patients with proctocolitis the rates of absorption of sodium and water by the colon were significantly reduced (Table). Potassium was secreted into the colonic lumen of the

\begin{tabular}{|c|c|c|c|c|c|}
\hline \multicolumn{3}{|c|}{ Potassium ( $\mu$-equiv/min) } & \multicolumn{3}{|l|}{ Water (ml/min) } \\
\hline Net & Out of Lumen & Into Lumen & Net & Out of Lumen & Into Lumen \\
\hline $\begin{array}{l}-17.0 \pm 3.6 \\
-12.0 \pm 5.8 \\
-8.8 \pm 7.0 \\
-17.2 \pm 4.5\end{array}$ & $\begin{array}{r}9 \cdot 9 \pm 3 \cdot 0 \\
6 \cdot 2 \pm 1 \cdot 8 \\
12 \cdot 6 \pm 4 \cdot 2 \\
6 \cdot 0 \pm 2 \cdot 1\end{array}$ & $\begin{array}{l}26 \cdot 9 \pm 4.4 \\
18 \cdot 2 \pm 7 \cdot 1 \\
21 \cdot 4 \pm 10 \cdot 7 \\
23 \cdot 2 \pm 5 \cdot 2\end{array}$ & $\begin{array}{l}+0.5 \pm 0.9 \\
-0.5 \pm 0.4 \\
+0.8 \pm 0.6 \\
+0.2 \pm 1.4\end{array}$ & $\begin{array}{r}13 \cdot 2 \pm 1 \cdot 1 \\
7 \cdot 6 \pm 1 \cdot 4 \\
10 \cdot 0 \pm 4 \cdot 0 \\
21 \cdot 2 \pm 0.8\end{array}$ & $\begin{array}{r}12 \cdot 7 \pm 0.9 \\
8 \cdot 1 \pm 1 \cdot 7 \\
9 \cdot 2 \pm 4 \cdot 1 \\
21.0 \pm 1.4\end{array}$ \\
\hline$-13.8 \pm 4.2$ & $8 \cdot 7 \pm \mathbf{3 \cdot 2}$ & $22.4 \pm 3.6$ & $+0.25 \pm 0.56$ & $13 \cdot 0 \pm 5.9$ & $12 \cdot 8 \pm 5 \cdot 8$ \\
\hline $\begin{array}{r}-5.2 \pm 6.5 \\
-7.2 \pm 4.5 \\
-7.7 \pm 4.0 \\
-1.2 \pm 4.3 \\
-4.7 \pm 3.5 \\
0 . \pm 1.7 \\
-0.5 \pm 3.6 \\
=3.4 \pm 3.6 \\
+5.8 \pm 2.4 \\
-7.1 \pm 3.2 \\
=0.3 \pm 7.5 \\
-6.1 \pm 1.0\end{array}$ & $\begin{array}{r}14.7 \pm 6.7 \\
14.7 \pm 2.6 \\
7.9 \pm 2.8 \\
9 \cdot 4 \pm 4.3 \\
8.0 \pm 2.5 \\
11.4 \pm 1 \cdot 8 \\
14.8 \pm 4.5 \\
9.0 \pm 6.0 \\
9.5 \pm 3.2 \\
12.1 \pm 0.5 \\
13.2 \pm 2.8 \\
13.0 \pm 2.0\end{array}$ & $\begin{aligned} 19.9 \pm 10.5 \\
21.9 \pm 2.5 \\
15.6 \pm 3.3 \\
10.6 \pm 6.6 \\
12.7 \pm 4.6 \\
11.4 \pm 1.8 \\
15.3 \pm 3.8 \\
12.3 \pm 5.0 \\
3.7 \pm 2.4 \\
19.2 \pm 3.7 \\
13.5 \pm 9.9 \\
19.1 \pm 2.8\end{aligned}$ & $\begin{array}{l}+1.4 \pm 0.9 \\
+1.6 \pm 0.8 \\
+2.3 \pm 0.7 \\
+2.1 \pm 0.8 \\
+2.1 \pm 0.3 \\
+2.3 \pm 0.3 \\
+2.5 \pm 0.7 \\
+2.1 \pm 1.3 \\
+1.1 \pm 0.5 \\
+2.8 \pm 0.5 \\
+1.0 \pm 0.5 \\
+1.8 \pm 0.2 \\
+1.0 \pm 0.3\end{array}$ & 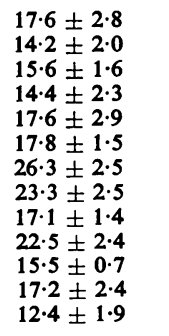 & $\begin{array}{l}16.1 \pm 2.7 \\
12.6 \pm 2.6 \\
13.3 \pm 1.4 \\
12.3 \pm 2.2 \\
15.5 \pm 2.7 \\
15.5 \pm 1.4 \\
23.8 \pm 2.5 \\
21.2 \pm 1.5 \\
16.0 \pm 1.2 \\
19.7 \pm 2.2 \\
14.6 \pm 1.0 \\
15.4 \pm 2.6 \\
11.4 \pm 1.7\end{array}$ \\
\hline$-3 \cdot 2 \pm 4.0$ & $11 \cdot 5 \pm 2 \cdot 6$ & $14.6 \pm 5.0$ & $+1.85 \pm 0.59$ & $17 \cdot 8 \pm 4 \cdot 0$ & $16 \cdot 0 \pm 3 \cdot 6$ \\
\hline $10 \cdot 6 \pm 2 \cdot 3$ & $2 \cdot 8 \pm 1 \cdot 6$ & $7 \cdot 8 \pm 2 \cdot 7$ & $1 \cdot 60 \pm 0 \cdot 3$ & $4 \cdot 8 \pm 2 \cdot 5$ & $3 \cdot 2 \pm 2 \cdot 4$ \\
\hline 4.54 & $1 \cdot 76$ & -2.84 & $-4 \cdot 83$ & 1.90 & $1 \cdot 35$ \\
\hline$<0.001$ & $>0.1$ & $<0.02$ & $<0.001$ & $>0.05$ & $>0.2$ \\
\hline
\end{tabular}

Table The mean rates $( \pm S D)$ of net transport and of unidirectional flux of sodium, potassium, and water in patients with proctocolitis and in healthy subjects continued 


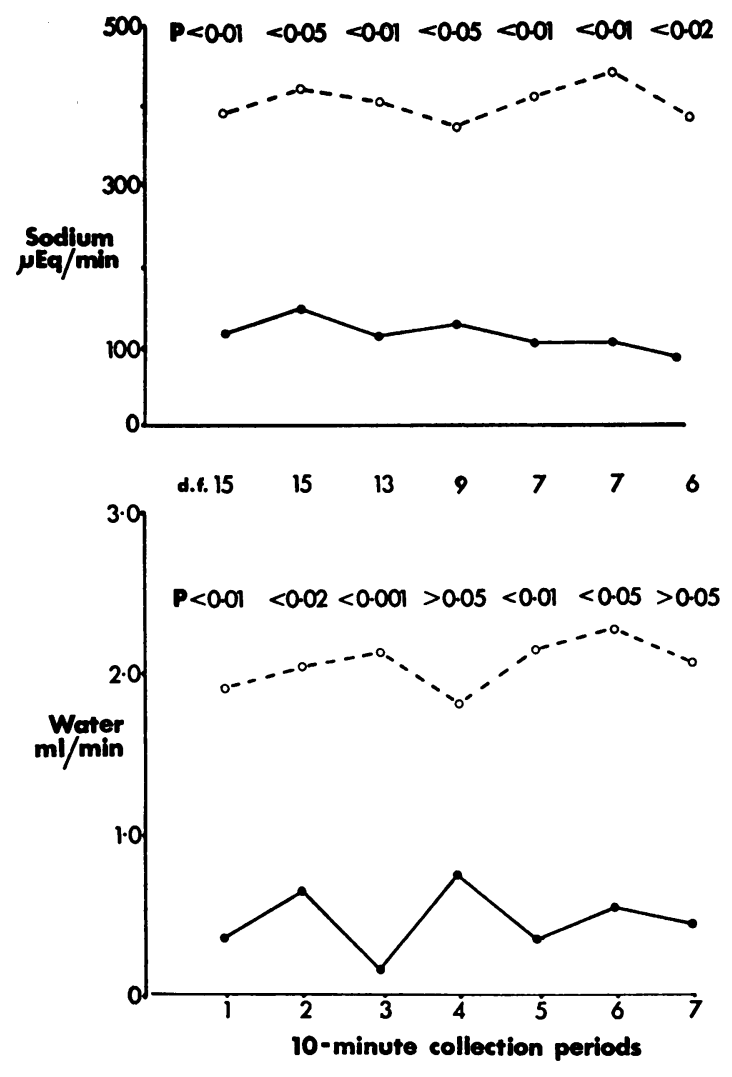

Fig. 1 The mean rates of absorption of sodium and water for consecutive 10-minute collection periods in healthy subjects $\left(\mathrm{O}_{---} \mathrm{O}\right)$ and patients with proctocolitis ( $-\longrightarrow$.

$\mathrm{P}$ represent the probability that there was no difference in mean rates, calculated for corresponding collection periods, between the two groups of subjects: d.f. denotes the degree of freedom.

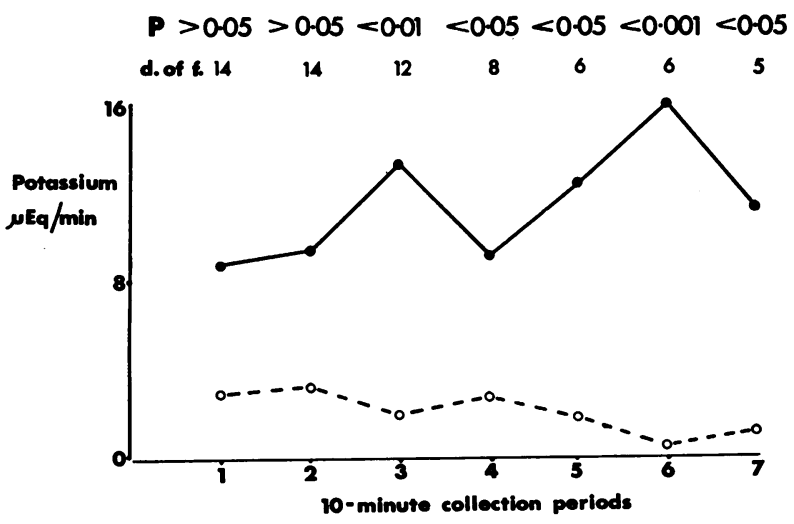

Fig. 2 The mean rates of secretion of potassium for consecutive collection periods in healthy subjects and patients with proctocolitis. The same conventions are used as in Figure 1. patients at a mean rate more than four times that found in healthy subjects.

The mean rates of absorption of sodium and water for each 10-minute collection period were relatively constant during the perfusion study in both healthy subjects and in patients with proctocolitis (Fig. 1). The ability of the ulcerated colon to absorb sodium and water was consistently impaired. The rates of secretion of potassium remained low and relatively constant in the healthy subjects (Fig. 2). In patients with proctocolitis the secretion of potassium was more variable, but, on almost every occasion, was significantly greater than the rates observed during corresponding times in healthy subjects.

\section{Unidirectional fluxes}

In diffuse proctocolitis the rate of movement of sodium out of the colonic lumen was diminished (Table). Reduction in the flux rates of potassium and water in this direction was also evident in the patients but did not produce statistically significant differences from those observed in the healthy subjects.

Sodium and potassium ions moved more rapidly into the lumen of the ulcerated colon. Water flux in this direction was not altered.

RELATIONSHIP BETWEEN NET SODIUM AND WATER TRANSPORT

In healthy subjects and in patients with proctocolitis, net transport of water was closely correlated with that of sodium (Fig. 3). In general when sodium was absorbed, water was absorbed; when sodium was secreted, so also was water. On only rare occasions was sodium absorbed and water secreted or vice versa. Because the $y$ intercept of the extrapolated regression line of water on sodium net absorption in healthy subjects was significantly different from zero $(P<0.02)$, it was concluded that in these subjects some water may be absorbed in the absence of sodium absorption. In contrast, in proctocolitis when sodium was not being absorbed, no water was absorbed $(P>0.05)$. Secretion of water and sodium was more common in proctocolitis, occurring on 15 out of 38 occasions. In both groups the relationship between the net transport of sodium and water was similar, there being no significant difference in the slope of the regression lines $(P>0 \cdot 1)$.

\section{Discussion}

Although under normal conditions most of the salt in the diet is absorbed in the small intestine, the small bowel has a limited capacity to conserve sodium (Kramer, 1966). Impairment of the colon's ability to absorb water and salt may, under a variety of circumstances, lead to increased losses of fluid and electrolytes from the body. 


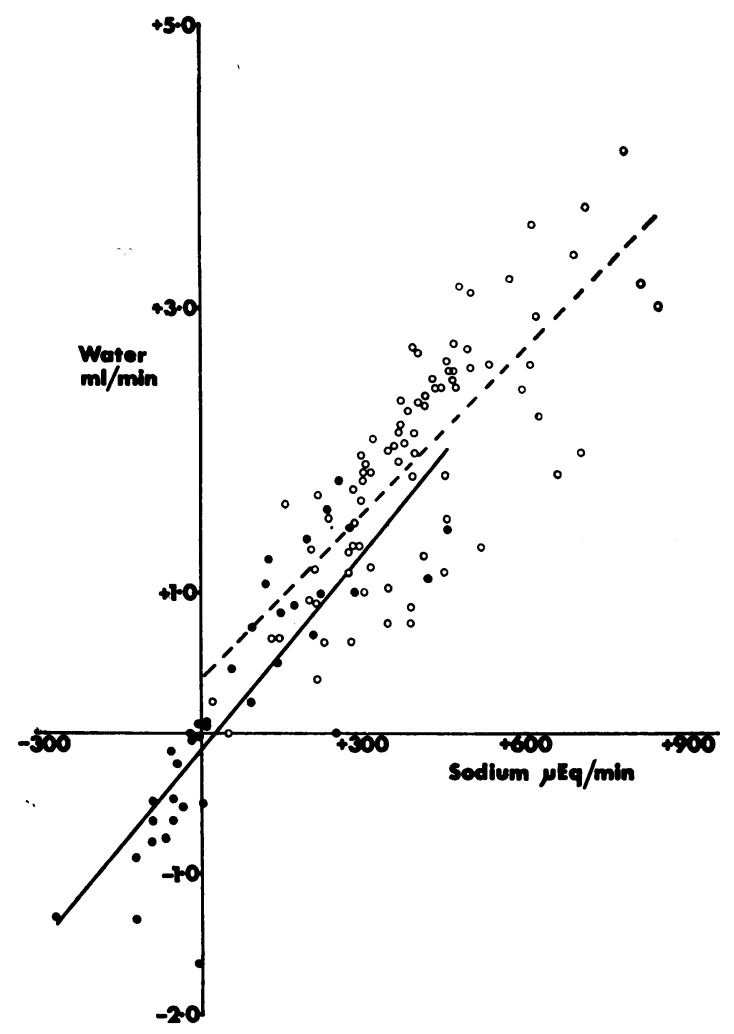

Fig. 3 Correlation between net sodium and net water transport in patients with proctocolitis (O) and in healthy subjects $(O)$. Each point represents the rate of net transport of sodium and water calculated for a single 10-minute collection period.

$$
\begin{aligned}
& \text { Healthy Subjects } \\
& \qquad \begin{array}{c}
\mathrm{H}_{2} \mathrm{O}=(3.98 \pm 0.36) \mathrm{Na}^{+} \\
\quad(0.37 \pm 0.15) \mathrm{ml} / \mathrm{min} \\
\boldsymbol{r}=0.78 \\
P<0.001
\end{array}
\end{aligned}
$$

The continuous line represents the regression line of water on sodium net transport in patients with proctocolitis and the dotted line the regression line in healthy subjects.

$$
\begin{aligned}
& \text { Proctocolitis } \\
& \qquad \begin{aligned}
\mathrm{H}_{2} \mathrm{O} & =(4.83 \pm 0.49) \mathrm{Na}^{-} \\
r & =0.85 \\
\mathrm{P} & <0.15 \pm 0.09) \mathrm{ml} / \mathrm{min}
\end{aligned}
\end{aligned}
$$

Until recently our knowledge of colonic function has largely been obtained by comparing the volume and content of the discharge from well established ileostomies with the composition of faeces of healthy subjects. From such studies it has been inferred that the colon, which each day receives from the ileum about $500 \mathrm{ml}$ chyme, containing 115-145 m-equiv per litre sodium and 6-30 m-equiv per litre potassium (Kanaghinis, Lubran, and Coghill, 1963), absorbs most of the sodium and water but at the same time secretes potassium and bicarbonate into its lumen (Annis and Alexander, 1952). However, the colon possesses a greater capacity to absorb sodium and water and to secrete potassium than is immediately apparent from these studies. By extrapolating the data obtained in the present investigation we calculate that the healthy colon can absorb as much as $\mathbf{5 6 0}$ m-equiv sodium and 2.7 litres water each day. This calculation assumes that the rates of absorption would remain constant if the perfusion had been continued for 24 hours. To our knowledge such prolonged perfusion of the colon has not been carried out, but neither we, whose studies lasted, on average, two and a half hours (Figs. 1 and 2), nor Levitan (1965), who perfused subjects for up to five hours, noticed any alteration in colonic absorption with time.

In diffuse proctocolitis the reserve capacity of the colon to absorb sodium and water is lost. Because of the reduction in the mean rate of absorption of sodium to one-third, and that of water to one-seventh, of those observed in healthy subjects (Table), the daily absorptive capacity of the large bowel was reduced to as little as 160 m-equiv sodium and $360 \mathrm{ml}$ water. This volume of fluid is less than that usually presented to the colon each day by the ileum. Indeed, in proctocolitis the volume of the ileal effluent may be greater than normal if the ileum is also affected by disease. The diarrhoea of proctocolitis, therefore, can be explained, in part at least, by the colon being severely impaired in its ability to absorb the salt and water delivered to it from the ileum.

Although impairment in colonic absorption of sodium and water in ulcerative colitis was also reported by Duthie et al (1964), they did not describe any alteration in the secretion of potassium. They were therefore unable to account for the considerable faecal losses of potassium that others (Welch et al, 1937; Lubran and McAllen, 1951; Coghill et al, 1956) have reported in cases of ulcerative colitis. Indeed, on occasion, ileostomy may have to be expedited to stem the loss of potassium in the stool (Brooke, 1958). We found that potassium was secreted into the colonic lumen four times more rapidly than in healthy subjects.

Hitherto the source of the potassium lost in the faeces of patients with proctocolitis has not been clearly defined. Welch et al (1937) suggested that the potassium was largely derived from desquamated intestinal mucosa, blood, and pus. This explanation was challenged by Lubran and McAllen (1951) who, by careful comparison of faecal nitrogen and potassium, concluded that release of potassium from cellular debris could not account entirely for the increased quantities of the electrolyte in the faeces. We consider that the present study provides additional evidence for this point of view. In this investigation, care was taken to prevent contamination of the luminal contents by the liberation of potassium from damaged cells. Accumulated cellular debris was 
removed by the prolonged initial perfusion of the colon. Secondly, neither blood nor mucus was evident in the rectal effluent of patients with proctocolitis. Moreover damage to the cells was minimized by the use of an isotonic test solution. Finally, cells which might have liberated potassium were quickly removed from the rectal effluent by prompt centrifugation. Although it cannot be denied that some of the potassium in the stool of patients with proctocolitis is derived from mucus, blood, and pus exuding into the colonic lumen, we consider that this is not the entire explanation and suggest that in proctocolitis the colonic transport of potassium is disturbed, leading to greater net losses of the electrolyte in the lumen of the bowel.

Changes in the unidirectional fluxes of water and electrolytes in proctocolitis may throw greater light upon the abnormalities in net transport which we have described above. Reduction in the rates at which sodium, and to a lesser extent water and potassium, left the colonic lumen, was probably caused by a diminution in the mucosal surface area available for absorption, because of the shortening and narrowing of the colon which are characteristic of proctocolitis. Duthie et al (1964) also noted a diminished movement of sodium and water out of the colonic lumen, but did not describe any change in the unidirectional flux of potassium. Reduction in the mucosal surface area of the colon does not explain the increased flux of electrolytes into the colonic lumen which we observed. From a study of this nature, we cannot determine the source of these electrolytes nor speculate how they are transferred into the lumen of the large intestine. To some extent at least, fluid and electrolytes must exude into the colon across its inflamed and ulcerated surface. The net result, however, of these changes in unidirectional movement is that the diseased colon becomes less absorptive and more secretory in function. Whether these changes are caused by a primary fault in the cellular processes of electrolyte transport or by alterations in the permeability characteristics of the colonic mucosa cannot be deduced from this study.

We do not claim that these changes in the colonic transport of water and electrolytes are specific to proctocolitis. Indeed similar abnormalities have been observed in Crohn's disease of the colon (Head, Heaton, and Kivel, 1969). We do not consider that the altered colonic transport of water and electrolytes in our patients with proctocolitis were caused by changes in body composition due to the loss of water and salt in the faeces. Extrarenal loss of water and sodium may, of course, lead to increased secretion of aldosterone and antidiuretic hormone, both of which can affect the colonic absorption of water and electrolytes (Levitan and Ingelfinger, 1965; Levitan and Mauer, 1968). However, we tried to minimize these secondary effects on the colon by ensuring that the patients were on a normal diet and were not depleted of water and electrolytes at the time of the study.

A close relationship between water and sodium absorption has been observed on many occasions both in animal experiments(CurranandSolomon, 1957) and in studies of the human small and large intestine (Sladen and Dawson, 1969; Devroede and Phillips, 1969b), probably because of a presumed dependence of water absorption on the transport of solute. This study demonstrates the close correlation between sodium and water absorption in the human colon and shows that despite alterations in the absorption of water and sodium in proctocolitis this correlation is preserved. Thus it would seem that even in diffuse disease the processes of absorption are similar to those in health but are changed in the direction of secretion.

Two defects of this study are the small number of patients with proctocolitis and the age and sex of the subjects with whom they were contrasted. For several reasons we were able to study only a few patients with diffuse proctocolitis. Such patients are not very common and not all the patients seen by us were suitable or volunteered for the investigation. Moreover, we were frequently frustrated by delay in the transit of the tube through the upper gastrointestinal tract; others have also observed delay in gastric and small intestinal transit in ulcerative colitis (Rosswick, Stedeford, and Brooke, 1966). The patients with proctocolitis and the healthy subjects are not strictly comparable because those in the contrast group were younger and were all male. We have not studied women of childbearing age because of the exposure of the pelvic organs to the rays emanating from the isotopes in the colon, even although the doses employed were small and the risk negligible. However, other studies without the use of radioactive isotopes have not demonstrated any change in colonic absorption with age or sex (unpublished observations).

The faecal losses of sodium and water in proctocolitis are clearly the result of impaired absorption of ileal contents during their passage along the colon. However, as the alterations in unidirectional fluxes indicate, the ulcerated colon is far from being an inert tube or passive conduit transferring the ileal content to the rectum unchanged. The colon in proctocolitis contributes significantly to the losses of water, sodium, and potassium in the faeces.

The patients and the healthy subjects, for whose consent and cooperation we are grateful, were studied in the University Department of Surgery, Royal Infirmary, Cardiff. We are grateful to Professor A. P. M. Forrest, for his interest and encouragement. We thank those consultant physicians and surgeons in South Wales who allowed us to examine patients under their care, particularly the late $\mathrm{Mr} \mathrm{D}$. $\mathrm{H}$. Jenkins of the Royal Infirmary, Cardiff. We are 
indebted to Dr H. Campbell and Mr T. Khosla for their statistical advice, and to Professors K. T. Evans and R. Mahler for allowing us to use apparatus in their departments. We thank Miss Margaret Davies for technical assistance and Mr M. S. Page and the staff of the Computer Department of the Welsh Regional Hospital Board for their help in preparing the computer program.

This work was carried out with the aid of a grant from the Medical Research Council.

Requests for reprints should be addressed to, Professor R. Shields, Department of Surgery, P.O. Box 147, Liverpool L69 3BX.

\section{References}

Annis, D., and Alexander, M. K. (1952). Differential absorption of electrolytes from the large bowel in relation to ureterosigmoid anastomosis. Lancet, 2, 603-606.

Berglund-Larsson, U. (1956). Determination of small amounts of deuterium oxide in water by infra-red spectroscopy. Acta chem. scand., 10, 701-702.

Brooke, B. N. (1958). Ileostomy chemistry. Dis. Colon Rect., 1, 3-14.

Code, C. F., and McIntire, F. C. (1956). Quantitative determination of histamine. Meth. biochem. Anal., 3, 49-95.

Coghill, N. F., Lubran, M., McAllen, P. M., Edwards, F., and Richenberg, C. S. (1956). Sodium and potassium absorption and excretion in patients with ulcerative colitis before and after colectomy. Gastroenterologia (Basel), 86, 724734.

Curran, P. F., and Solomon, A. K. (1957). Ion and water fluxes in the ileum of rats. J. gen. Physiol., 41, 143-168.

Devroede, G. J., and Phillips, S. F. (1969a). Studies of the perfusion technique for colonic absorption. Gastroenterology, $56,92-100$.

Devroede, G. J., and Phillips, S. F. (1969b). Conservation of sodium, chloride and water by the human colon. Gastroenterology, 56, 101-109.

Duthie, H. L., Watts, J. M., de Dombal, F. T., and Goligher, J. C. (1964). Serum electrolytes and colonic transfer of water and electrolytes in chronic ulcerative colitis. Gastroenterology, 47, 525-530.

Gallagher, N. D., Goulston, S. J. M., Wyndham, N., and Morrow, W. (1962). The management of fulminating ulcerative colitis. Gut, 3, 306-311.

Harris, J., and Shields, R. (1967). The absorption and secretion of water, sodium and potassium by the intact human colon in ulcerative colitis. (Abstr.) Gut, 8, 633 .

Head, L. H., Heaton, J. W., Jr., and Kivel, R. M. (1969). Absorption of water and electrolytes in Crohn's disease of the colon. Gastroenterology, 56, 571-579.

Hydén, S. (1955). A turbidometric method for the determination of higher polyethylene glycols in biological materials. K. LandtbrHögsk. Annlr., 22, 139-145.

Kanaghinis, T., Lubran, M., and Coghill, N. F. (1963). The composition of ileostomy fluid. Gut, 4, 322-338.

Kramer, P. (1966). The effect of varying sodium loads on the ileal excreta of human ileostomized subjects. J. clin. Invest., $45,1710-1718$

Lennard-Jones, J. E., and Vivian, A. B. (1960). Fulminating ulcerative colitis. Recent experience in management. Brit. med. J., 2, 96-102.

Levitan, R. (1965). Salt and water absorption from the normal human colon: effect of 9-alpha fluorohydrocortisone administration. J. Lab. clin. Med., 69, 558-564.

Levitan, R., Fordtran, J. S., Burrows, B. A., and Ingelfinger, F. J. (1962). Water and salt absorption in the human colon. J. clin. Invest., 41, 1754-1759.

Levitan, R., and Ingelfinger, F. J. (1965). Effect of $d$-aldosterone on salt and water absorption from the intact human colon. J. clin. Invest., 44, 801-808.

Levitan, R., and Mauer, I. (1968). Effect of intravenous antidiuretic hormone administration on salt and water absorption from the human colon. J. Lab. clin. Med., 72, 739-746.

Lubran, M., and McAllen, P. M. (1951). Potassium deficiency in ulcerative colitis. Quart. J. Med., 20, 221-232.

Medical Research Council (1964). Report for the Year 1962-3, p. 21. H.M.S.O. London.

Rosswick, R. P., Stedeford, R. D., and Brooke, B. N. (1966), New methods of studying intestinal transit times. Gut, 8, 195-196.
Shields, R. (1964). Surgical aspects of the absorption of water and electrolytes by the intestine. Monogr. surg. sci., 1, 119-172.

Shields, R. (1966). Absorption and secretion of electrolytes and water by the human colon, with particular reference to benign adenoma and papilloma. Brit. J. Surg., 53, 893-897.

Shields, R., Harris, J., and Davies, M. W. (1968). Suitability of polyethylene glycol as a dilution indicator in the human colon. Gastroenterology, 54, 331-333.

Shields, R., Mulholland, A. T., and Elmslie, R. G. (1966). Action of aldosterone upon the intestinal transport of potassium, sodium and water. Gut, 7, 686-696.

Sladen, G. E., and Dawson, A. M. (1969). Interrelationships between the absorptions of glucose, sodium and water by the normal human jejunum. Clin. Sci., 36, 119-132.

Truelove, S. C., and Witts, L. J. (1955). Cortisone in ulcerative colitis: Final report on a therapeutic trial. Brit. med. J., 2, 1041-1048.

Veall, N., and Vetter, H. (1958). Radioisotope Techniques in Clinical Research and Diagnosis. Butterworth, London.

Visscher, M. B., Fetcher, E. S., Carr, C. W., Gregor, H. P., Bushey, M. S., and Barker, D. E. (1944a). Isotopic tracer studies on the movement of water and ions between intestinal lumen and blood. Amer. J. Physiol., 142, 550-575.

Visscher, M. B., Varco, R. H., Carr, C. W., Dean, R. B., and Erickson, D. (1944b). Sodium ion movement between the intestinal lumen and the blood. Amer. J. Physiol., 141, 488-505.

Welch, C. S., Adams, M., and Wakefield, E. G. (1937). Metabolic studies on chronic ulcerative colitis. J. clin. Invest., 16, 161-168. 